\title{
Signal Transduction across the Nuclear Envelope: Role of the LINC Complex in Bidirectional Signaling
}

\author{
Miki Hieda \\ Department of Medical Technology, Ehime Prefectural University of Health Sciences, 543 Takooda, Tobecho, \\ Ehime 791-2102, Japan; mikihieda@gmail.com; Tel.: +81-89-958-2111; Fax: +81-89-958-2177
}

Received: 23 December 2018; Accepted: 1 February 2019; Published: 4 February 2019

\begin{abstract}
The primary functions of the nuclear envelope are to isolate the nucleoplasm and its contents from the cytoplasm as well as maintain the spatial and structural integrity of the nucleus. The nuclear envelope also plays a role in the transfer of various molecules and signals to and from the nucleus. To reach the nucleus, an extracellular signal must be transmitted across three biological membranes: the plasma membrane, as well as the inner and outer nuclear membranes. While signal transduction across the plasma membrane is well characterized, signal transduction across the nuclear envelope, which is essential for cellular functions such as transcriptional regulation and cell cycle progression, remains poorly understood. As a physical entity, the nuclear envelope, which contains more than 100 proteins, functions as a binding scaffold for both the cytoskeleton and the nucleoskeleton, and acts in mechanotransduction by relaying extracellular signals to the nucleus. Recent results show that the Linker of Nucleoskeleton and Cytoskeleton (LINC) complex, which is a conserved molecular bridge that spans the nuclear envelope and connects the nucleoskeleton and cytoskeleton, is also capable of transmitting information bidirectionally between the nucleus and the cytoplasm. This short review discusses bidirectional signal transduction across the nuclear envelope, with a particular focus on mechanotransduction.
\end{abstract}

Keywords: LINC complex; nuclear envelope; mechanotransduction; SUN protein; KASH protein

\section{Introduction}

The cytoskeleton physically connects the plasma membrane with the nucleus; therefore, the nucleus responds to mechanical stimuli originating from outside of the cell after its propagation though the cytoskeleton. Integrins are receptors for extracellular matrix proteins and assemble into large macromolecular complexes known as focal adhesions (FAs), which connect the extracellular matrix to intracellular actin bundles [1]. An association between integrins, the cytoskeleton, and the nucleus was reported more than 20 years ago [2]. Integrins also act as mechanosensors in the plasma membrane and are critical for the organization of multiple nuclear components, such as chromatin and nucleoli [3-5]. Investigation of the interconnected integrin-cytoskeleton-nucleus mechanotransduction pathway has largely focused on the outside-in signals that initiate at the plasma membrane and are transferred to the nucleus (Figure 1, inside-out signaling). However, recent data show that the nucleus also plays a role as an information submission source (Figure 1, inside-out signaling), which is critical for the cells to sense and respond to the mechanical properties of their environment [6-8]. 


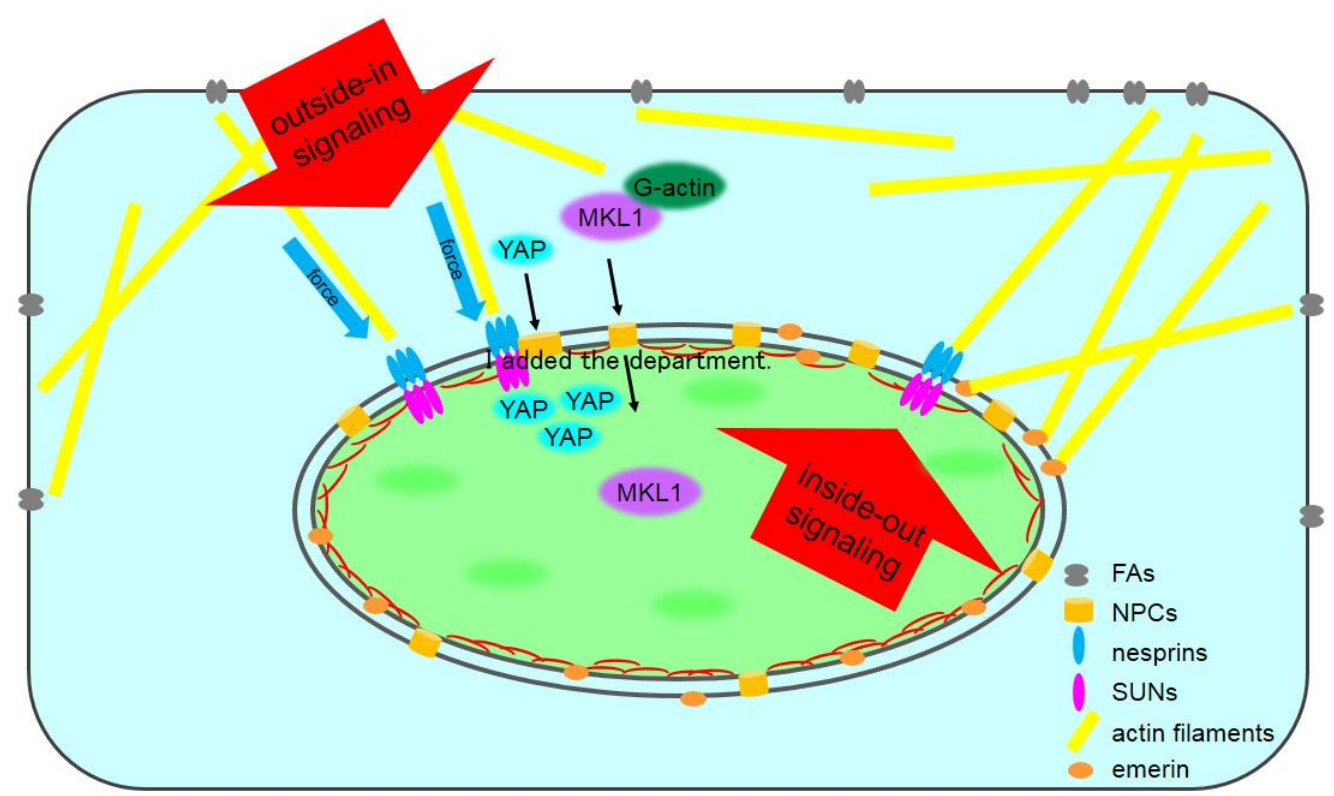

Figure 1. A model of Linker of Nucleoskeleton and Cytoskeleton (LINC) complex-mediated inside-out and outside-in signaling pathways. An enormous number of signaling pathways are integrated within cells. Outside-in signaling pathways, which originate within the cytoplasm or extracellular environment and terminate within the nucleus, can be roughly categorized into two groups. In the first pathway, mechanical stimuli are directly transferred to the nucleus via the LINC complex. The second pathway utilizes transcription factors such as Yes-associated protein (YAP) and megakaryoblastic leukemia 1 (MKL1) that shuttle between the cytoplasm and the nucleus through the nuclear pore complex (NPC). More importantly, the nucleus also plays a role as an information submission source. Inside-out signaling results in the transfer of signals from the nucleoplasm to the cytoplasm across the nuclear envelope (NE). SUN domain: Sad1/UNC-84.

The nucleus is mechanically integrated with the cytoskeleton via the Linker of Nucleoskeleton and Cytoskeleton (LINC) complexes, which are evolutionarily conserved nuclear envelope (NE)-spanning molecular bridges. The LINC complexes are comprised of the Sad1/UNC-84 (SUN) domain-containing proteins located on the inner nuclear membrane and the Klarischt/ANC-1/SYNE homology (KASH) domain-containing proteins, known as nuclear envelope spectrin repeat protein (nesprins), which are found on the outer nuclear membrane. Mammals encode five SUN proteins (SUN1 5) and six KASH proteins (nesprins-1-4, KASH5, and lymphocyte-restricted membrane protein) [9-15]. SUN proteins interact with lamins and chromatin in the nucleus, whereas nesprins associate with the various elements of the cytoskeleton in the cytoplasm [16-18]. Thus, the LINC complex has diverse functions, including nuclear migration [19], maintenance of the proper nuclear morphology and positioning of the nucleus $[20,21]$, maintenance of the centrosome-nucleus connection via direct or indirect interaction [22-26], DNA repair [27,28], cell migration [29-31], and movement of chromosomes within the nucleus during meiosis [32]. In addition, the LINC complex transmits various signals from the cell surface to the nucleus [33] as well as from the nucleus to the cytoplasm [6-8]. This review summarizes the current understanding of bidirectional signal transduction across the NE, with an emphasis on the LINC complex and mechanical signaling from extracellular environment via FAs.

\section{Outside-in Signaling across the NE}

Outside-in signaling pathways across the NE, that originate within the cytoplasm or extracellular environment and terminate within the nucleus, can be roughly categorized into two groups. In the first pathway, mechanical stimuli are directly transferred to the nucleus via the LINC complex. The second pathway utilizes biochemical molecules that shuttle between the cytoplasm and the nucleus through the nuclear pore complex (NPC). In this section, these two pathways which mediate 
with mechanotransduction from the extracellular environment and the cytoplasm to the nucleus will be discussed. Lamins are intermediate filament proteins and form the nuclear lamina scaffold, which localizes adjacent to the inner nuclear membrane. Lamin A and lamin C (Lamin A/C) participates in various cellular responses to mechanical stimuli, including regulation of transcription, modulation of nuclear and cellular stiffness, and regulation of nuclear morphology [34]. Because this review focuses on the transducers of the LINC complex, for information about functions of lamin A/C in mechanotransduction, please refer to an excellent review that has been recently published by Osmanagic-Myers et al. [35].

\subsection{Responses of the Nucleus Induced by Mechanical Stimuli}

When mechanical force is applied to the extracellular domain of integrins present on the plasma membrane, alterations of the nuclear morphology are induced, indicating that mechanical stress can be transmitted from the extracellular matrix (ECM) to the nucleus [2]. Other mechanical stimuli, such as stretch and compression, impact nuclear shape and the organization of nucleoplasmic structures, such as chromatin and nucleoli [36-41]. Here, actin filaments and intermediate filaments are involved in the transfer of mechanical stimuli to the nucleus. Poh et al. showed that when a force of several nanonewtons was applied to cell surface integrins using magnetic beads coated with Arg-Gly-Asp (RGD) peptide, which is an established integrin ligand, it induced rapid (less than $1 \mathrm{~s}$ ) dissociation of two major structural proteins, coilin and SMN, from the Cajal body [41]. Disruption of the actin cytoskeleton or depletion of lamin A/C abolishes this response, suggesting the presence of an integral signaling pathway between integrins and nuclear structures [41]. The application of mechanical stress to the integrins within the plasma membrane triggers an increase in cellular stiffness [42,43]. A similar stiffening response was recently demonstrated by the Burridge group to occur in isolated HeLa cell nuclei that were exposed to mechanical forces applied via magnetic tweezers that pulled on magnetic beads coated with anti-nesprin-1 antibodies, which were bound to the outer nuclear membrane [44].

In addition to being able to sense and respond to externally applied mechanical stimuli, cells themselves exert mechanical forces upon their environment via the transmission of actomyosin-generated tension through cell-cell and cell-substrate adhesions. Recently, two research groups showed that the actin filament-severing proteins actin depolymerizing factor (ADF) and cofilin were essential for normal nuclear structure in tissues and in cultured cells. ADF and cofilin-1, which are products of separate genes, negatively regulate non-muscle myosin-II activity through competitive inhibition for binding to F-actin $[45,46]$. Depletion of both ADF and cofilin- 1 causes various nuclear defects including aberrant nuclear morphology, discontinuities in the nuclear lamina, and a reduction of heterochromatin at the nuclear periphery (detected by the accumulation of H3K27me3, H4K20me3 and topo3). Depletion of nesprin-2 giant (nesprin-2G) or lamin A/C using small interfering RNA prevents nuclear abnormalities from occurring in cells simultaneously depleted of cofilin-1 and ADF showing that cytoplasmic actomyosin-generated mechanical stimuli are transferred to the nucleus and regulate nuclear morphology.

In addition to its impact on nuclear architecture, mechanical stress influences the posttranslational modification of histones (e.g., acetylation and methylation) as well as the dynamics and intranuclear localization of heterochromatin [47]. The genome is exposed to mechanical stresses originating from the cytoplasm, which can be transmitted either via the LINC complex or through the contact sites between the NE and chromatin. These stresses affect the localization of histone-modifying enzymes that indirectly modulate chromatin organization via epigenetic modifications. For example, inhibition of actomyosin contractility induces the nuclear translocation of the histone deacetylase HDAC3, resulting in a decrease in the levels of histone acetylation [48,49]. Another example of this phenomenon is that T-cell adhesion through integrin $\alpha 4 / \beta 1$ induces the recruitment of the histone methyltransferase G9a to the NE, resulting in an increase in the level of the histone post-translational modification H3K9me2/3 [50]. These altered histone modifications can contribute to physical properties of the nucleus. For instance, nuclear peripheral heterochromatin may enhance the structural robustness 
of the nucleus and strengthen its ability to resist physical stress, such as mechanical forces exerted during cell migration or in the mechanically active tissues [51,52]. Moreover, altered higher order chromatin organization induced by changes in histone modification has a significant effect on gene expression [53] and thus mechanical stress can also regulate gene expression [54]. For information related to transcriptional regulation by mechanical stimuli, please refer to recent excellent review written by Uhler and Shivashankar [55].

\subsection{Outside-In Signaling via the LINC Complex}

Mechanical stretch induces the proliferation of $\mathrm{C} 2 \mathrm{C} 12$ myoblast cells, but the disruption of the LINC complex by overexpression of dominant-negative nesprin or SUN proteins constructs suppresses this phenomenon [56]. This result indicates that there is a mechanotransduction pathway to the nucleus through the LINC complex. The perinuclear actin cap covers the apical surface of the nucleus and regulates nuclear shape in adherent cells [36]. Nesprin-2G and nesprin-3 anchor the perinuclear actin cap, which is a highly organized array of parallel contractile actin filament bundles that contain phosphorylated non-muscle myosin II regulatory light chain and the F-actin crosslinker $\alpha$-actinin, to the apical surface and lateral sides of the interphase nucleus [57]. The perinuclear actin cap is not equivalent to the dorsal perinuclear actin cables because of their highly specified components [36]. Wirtz's group demonstrated that overexpression of a dominant negative KASH construct or the depletion of the LINC complex proteins nesprin-2G or nesprin-3 inhibits the assembly of the perinuclear actin cap and that perinuclear actin cap associated focal adhesions (ACAFAs) differ from conventional FAs in morphology, size, and spatial distribution $[33,36,58,59]$. Intriguingly, the perinuclear actin cap is formed in response to shear stresses 50 orders of magnitude lower and faster than biochemical stimulation in adherent cells [33]. These data clearly show the existence of an interconnected physical pathway of the integrin-cytoskeleton-LINC complex, which enables ultrafast mechanotransduction from the extracellular environment to the nucleus. In addition, transmembrane actin-associated nuclear (TAN) lines are linear arrays of nesprin-2G/SUN2 LINC complexes, which associate with perinuclear actin cables on the dorsal surface of nuclei in migrating fibroblasts and myoblasts. Formin homology 2 domain containing 1 (FHOD1), Samp-1, and torsinA are TAN line components [60-63]. TAN lines are required for rearward nuclear movement during centrosome orientation in migrating fibroblasts and myoblasts [29,60]. Moreover, Burridge's group directly applied mechanical stimulus to nesprin-1 on the surface of isolated nucleus and demonstrated the existence of a mechano-transduction pathway into the nucleus via the LINC complex [44]. This study also revealed that lamin A/C and its binding partner, an inner nuclear membrane protein, emerin, participates in local nuclear stiffening, which is induced by mechanical stimuli. In response to the mechanical pulling of nesprin-1, emerin undergoes tyrosine phosphorylation by Src. This phosphorylation strengthens the connection between lamin $\mathrm{A} / \mathrm{C}$ and the LINC complex, which is important for the expression of mechanosensitive genes and the assembly of stress fibers [44]. Using fluorescence resonance energy transfer-based tension biosensors, Arsenovic et al., (2016) demonstrated that nesprin-2G is subject to mechanical tension in adherent fibroblasts with the highest level of force on the apical and equatorial planes of the nucleus. This tension was observed to be reduced in fibroblasts obtained from patients with Hutchinson-Gilford progeria syndrome [64].

\subsection{Outside-In Signaling through the NPC}

Mechanical stress applied to the cell surface induces alterations in protein conformation and post-translational modification as we as the assembly of protein complexes. All these processes can modulate protein localization and activate biochemical signaling pathways [65,66]. Megakaryoblastic leukemia 1 (MKL1), which is also known as myocardin-related transcription factor A (MRTF-A) or MAL, is a mechanosensitive transcriptional coactivator of the serum response factor (SRF) [67]. Its localization is regulated via changes in actin polymerization. MKL1 is localized in the cytoplasm by its interaction with monomeric actin and by its constitutive nuclear export [68-73]. Mechanical 
stimulation induces RhoA-mediated actin polymerization and the dissociation of MKL1 from monomeric actin, resulting in the accumulation of MKL1 in the nucleus and the up-regulation of SRF-inducible genes including actin, SRF, and vinculin [68-73]. These proteins regulate cellular motility and contractility [74]. In addition, emerin is a crucial modulator of actin polymerization and absence of emerin or its binding partner lamin A/C results in disturbed actin dynamics and impaired MKL1 signaling $[75,76]$. Moreover, nuclear actin was observed to be more mobile in $L M N A^{-/-}$cells than in wild-type controls. The nuclear translocation and downstream signaling of MKL1 is impaired in cells lacking in lamin A/C, but not in the LINC complex [76]. This is consistent with the suggestion that lamin A/C, but not the LINC complex, is required for the activation of the mechanosensitive genes which encode the proteins vinclulin, tailin, and Egr-1 in heart tissue and cultured fibroblasts from mice $[37,77,78]$.

Recent exciting work demonstrates that mechanical stimuli directly regulate nuclear-cytoplasmic transport via the NPC [79]. The inner lumen of NPC comprises a disorganized, flexible meshwork of proteins containing phenylalanine-glycine repeats (FG-Nups), which suppresses protein diffusion [80-82]. Yes-associated protein (YAP) is a mechanosensitive transcriptional regulator that has physiological and pathological functions [83-85]. The intracellular localization of YAP is regulated by the Hippo signaling pathway [86] and mechanical stresses such as ECM rigidity and shear stress [87-91]. Mechanical stress induces the nuclear translocation of YAP in a tailin-, actomyosin-, and LINC complex-dependent, but Hippo signaling-independent manner. Elosegui-Artola et al. demonstrated that there is a faster nuclear entry of YAP in cells grown on stiffer substrates. Nuclei in cells grown on stiff substrates are more flat than those in cells grown on soft substrates, and mechanical stimuli increase NPC permeability, allowing YAP to more readily enter the nucleus [79]. They also showed that the LINC complex was required for the increase in the nuclear translocation of YAP observed in cells grown on stiff substrates. It remains unclear which SUN protein(s) is involved in the regulation of NPC permeability, while SUN1 but not SUN2 colocalizes with NPC and interacts with components of NPC [31,92-94]. This mechanism might be generally applicable beyond YAP and further investigation of the interplay between outside-in signaling through the NPC and outside-in signaling via the LINC complex is needed.

\section{Effects of NE on the Cytosolic Cytoskeleton}

Recent evidence suggests that the LINC complex signals not only from the cytoplasm into the nucleus but also from the nucleus to the cytoplasm. In this section, effects of the LINC complex on the cytoskeleton and inside-out signaling through the LINC complex are discussed.

\subsection{The LINC Complex Affects the Organization of the Cytoskeleton}

Disruption of the LINC complex impairs the dynamics and organization of the actin cytoskeleton and consequently cellular mechanics $[29,36,37,58,77,95,96]$. For example, expression of dominant negative nesprin alters the localization of actin and vimentin filaments as well as suppresses the migration of mouse embryonic fibroblasts [37]. The LINC complex-associated proteins, emerin, torsin $\mathrm{A}$, and lamim $\mathrm{A} / \mathrm{C}$, also influence cytoskeleton dynamics. Expression of phosphoresistant emerin mutant decreases the number of actin bundles [44], while impaired lamin A/C function alters actin cytoskeleton around the nucleus when cells are cultured on a rigid substrate [77]. In addition, outer nuclear membrane-localized emerin associates with non-muscle myosin IIB and organizes actin flow for nuclear movement and centrosome orientation in migrating fibroblasts, suggesting a novel function for the nuclear envelope in organizing directional actin flow and cytoplasmic polarity [97]. TorsinA-depleted NIH3T3 fibroblasts displayed impaired retrograde flow of perinuclear actin cables [63]. Dysfunction of the LINC complex affects not only cytoskeletal organization, but also cellular adhesion $[30,98,99]$. Depletion of nesprin- 1 in endothelial cells increases the number of FAs, traction forces and, nuclear height [30]. SUN2 contributes to the mechanical integrity of intercellular adhesions in mammalian epidermal keratinocytes [98]. Knockdown of the LINC complex 
components nesprin-2 or SUN1 leads to a substantial increase in the prominence of the adhesion domain at the opposite end of the invadopodia [99]. Moreover, LINC complexes influence microtubule (MT) organization as well. Gomes group has used the proximity-dependent biotin identification (BioID) method and revealed that muscle cell specific nesprin-1 isoform, nesprin- $1 \alpha$ interacts with several centrosomal proteins including Akap450, Pcm1, and pericentrin. They also showed that nesprin-1 $\alpha$ regulates MT nucleation [100]. In Drosophila, KASH domain protein Klarsicht regulates MT stability and integrin localization during collective cell migration [101]. These results indicate a physical role for the nucleus as anchoring point for cytoplasmic cytoskeletal elements.

\subsection{Inside-Out Signaling via the LINC Complex}

Recent papers have described several pathways in which the LINC complex signals to the cytoplasm, though detailed molecular mechanisms have not been well understood. Carroll's group showed that SUN2 promotes the assembly of FAs by activating RhoA, while SUN1 antagonizes SUN2 and suppresses RhoA activation and FA assembly [6]. Coirault and her colleagues demonstrated that muscle precursor cells expressing mutant lamin A/C $\left(L M N A^{\Delta K 32}\right)$ or nesprin-1 ${ }^{\triangle \mathrm{KASH}}$ had reduced ability to adapt to the rigidity of their environment. These cells exhibited contractile stress fiber accumulation, increased number of FAs and higher traction force on soft subtrates, which mimic physiological muscle stiffness. Inhibition of rho-associated protein kinase (ROCK) or a ROCK-dependent actin remodeling regulator, FHOD1, rescued the morphology of mutant cells, showing that functional integrity of lamin A/C and nesprin-1 is required to modulate activity of FHOD1 [7]. Chavrier and his colleges have shown that the nucleus-centrosome linkage of nesprin-2 and dynein adaptor Lis1 regulates the trafficking of MT1-MMP, one of matrix metalloproteinase family members, from the late endosomal/lysosomal storage compartments to the cell surface. The finding suggests that the LINC complex may also contribute to the persistence of malignancies and metastasis [8]. However, it has been shown that most of the LINC complex components are down-regulated in several types of cancer tissues ([102], unpublished data); thus, for the LINC complex to function during cancer metastasis, a more intricate regulation might exist. Emerin is present at both inner and outer nuclear membranes where it interacts with lamins and the cytosleketon, respectively [103]. The Wickström group recently showed that mechanical forces drive the enrichment of emerin in the outer nuclear membrane of epidermal stem cells, which is accompanied by the recruitment of muscle myosin IIA (NMIIA) to and the polymerization of actin at the nuclear surface. As a result, there is a reduction in the level of actin within the nucleus, resulting in the attenuation of transcription. They also show that the corresponding decrease of emerin at the inner nuclear membrane leads to a switch from H3K9me2/3 on constitutive heterochromatin to H3K27me3 as well as impaired anchorage of heterochromatin to the nuclear periphery [104]. Therefore, the NE may function as an integrator of cytoskeletal and nuclear functions.

\section{Concluding Remarks}

Recent data suggest that, like the cell-ECM boundary, the NE is a dynamic stimuli-sensitive interface between the cytoplasm and chromatin [105]. The LINC complex, which is localized at the NE, acts in a variety of signaling pathways between the cytoplasm and the nucleus. Currently the mechanisms responsible for regulating the assembly of functional LINC complexes remain poorly defined, although several lines of evidence identify several candidates for LINC complex regulators including intraluminal calcium, the redox environment of the $\mathrm{NE}$, torsin $\mathrm{A}$, and ubiquitinylation [63,106-108]. Finally, an analogy between FAs and LINC complexes can be drawn. Similar to the mechanical stimuli-dependent assembly of FAs, mechanical stresses applied to the nucleus via the cytoskeleton recruit the LINC complex and lamin A/C to specific indentation sites under stress fibers that exert force on the NE [109]. In addition, heterochromatin-related histone modifications are interestingly upregulated prior to and during cell migration $[52,110,111]$. Thus, in a similar manner to integrin-mediated inside-out signaling, it can be hypothesized that the chromatin 
signature might regulate the functional assembly of LINC complexes and their ability to transduce signals across the NE.

Funding: This work was supported by JSPS KAKENHI Grant Number 18K06226.

Conflicts of Interest: The author declares no conflict of interest.

$\begin{array}{ll}\text { Abbreviations } \\ \text { NE } & \text { nuclear envelope } \\ \text { LINC complex } & \text { Linker of Nucleoskeleton and Cytoskeleton } \\ \text { lamin A/C } & \text { Lamin A and lamin C } \\ \text { MT } & \text { microtubule } \\ \text { SUN domain } & \text { Sad1/UNC-84 } \\ \text { KASH } & \text { Klarischt/ANC-1/SYNE } \\ \text { nesprin } & \text { nuclear envelope spectrin repeat protein } \\ \text { MT } & \text { microtubule } \\ \text { FHOD1 } & \text { formin homology 2 domain containing } 1 \\ \text { FA } & \text { focal adhesion } \\ \text { NPC } & \text { nuclear pore complex } \\ \text { ADF } & \text { depolymerizing factor } \\ \text { Nesprin-2G } & \text { nesprin-2 giant }\end{array}$

\section{References}

1. Wolfenson, H.; Lavelin, I.; Geiger, B. Dynamic regulation of the structure and functions of integrin adhesions. Dev. Cell 2013, 24, 447-458. [CrossRef] [PubMed]

2. Maniotis, A.J.; Chen, C.S.; Ingber, D.E. Demonstration of mechanical connections between integrins, cytoskeletal filaments, and nucleoplasm that stabilize nuclear structure. Proc. Natl. Acad. Sci. USA 1997, 94, 849-854. [CrossRef] [PubMed]

3. Grashoff, C.; Hoffman, B.D.; Brenner, M.D.; Zhou, R.; Parsons, M.; Yang, M.T.; McLean, M.A.; Sligar, S.G.; Chen, C.S.; Ha, T.; et al. Measuring mechanical tension across vinculin reveals regulation of focal adhesion dynamics. Nature 2010, 466, 263-266. [CrossRef] [PubMed]

4. Maya-Mendoza, A.; Bartek, J.; Jackson, D.A.; Streuli, C.H. Cellular microenvironment controls the nuclear architecture of breast epithelia through $\beta 1$-integrin. Cell Cycle 2016, 15, 345-356. [CrossRef] [PubMed]

5. Madrazo, E.; Conde, A.C.; Redondo-Muñoz, J. Inside the Cell: Integrins as New Governors of Nuclear Alterations? Cancers 2017, 9, 82. [CrossRef] [PubMed]

6. Thakar, K.; May, C.K.; Rogers, A.; Carroll, C.W. Opposing roles for distinct LINC complexes in regulation of the small GTPase RhoA. Mol. Biol. Cell 2017, 28, 182-191. [CrossRef] [PubMed]

7. Schwartz, C.; Fischer, M.; Mamchaoui, K.; Bigot, A.; Lok, T.; Verdier, C.; Duperray, A.; Michel, R.; Holt, I.; Voit, T.; et al. Lamins and nesprin-1 mediate inside-out mechanical coupling in muscle cell precursors through FHOD1. Sci. Rep. 2017, 7, 1253. [CrossRef] [PubMed]

8. Infante, E.; Castagnino, A.; Ferrari, R.; Monteiro, P.; Agüera-González, S.; Paul-Gilloteaux, P.; Domingues, M.J.; Maiuri, P.; Raab, M.; Shanahan, C.M.; et al. LINC complex-Lis1 interplay controls MT1-MMP matrix digest-on-demand response for confined tumor cell migration. Nat. Commun. 2018, 9, 2443. [CrossRef]

9. Crisp, M.; Liu, Q.; Roux, K.; Rattner, J.B.; Shanahan, C.; Burke, B.; Stahl, P.D.; Hodzic, D. Coupling of the nucleus and cytoplasm: Role of the LINC complex. J. Cell Biol. 2006, 172, 41-53. [CrossRef]

10. Warren, D.T.; Zhang, Q.; Weissberg, P.L.; Shanahan, C.M. Nesprins: Intracellular scaffolds that maintain cell architecture and coordinate cell function? Expert Rev. Mol. Med. 2005, 7, 1-15. [CrossRef]

11. Malone, C.J.; Fixsen, W.D.; Horvitz, H.R.; Han, M. UNC-84 localizes to the nuclear envelope and is required for nuclear migration and anchoring during C. elegans development. Development 1999, 126, 3171-3181. [PubMed]

12. Hodzic, D.M.; Yeater, D.B.; Bengtsson, L.; Otto, H.; Stahl, P.D. Sun2 is a novel mammalian inner nuclear membrane protein. J. Biol. Chem. 2004, 279, 25805-25812. [CrossRef] [PubMed] 
13. Shao, X.; Tarnasky, H.A.; Lee, J.P.; Oko, R.; van der Hoorn, F.A. Spag4, a novel sperm protein, binds outer dense-fiber protein Odf1 and localizes to microtubules of manchette and axoneme. Dev. Biol. 1999, 211, 109-123. [CrossRef] [PubMed]

14. Frohnert, C.; Schweizer, S.; Hoyer-Fender, S. SPAG4L/SPAG4L-2 are testis-specific SUN domain proteins restricted to the apical nuclear envelope of round spermatids facing the acrosome. Mol. Hum. Reprod. 2011, 17, 207-218. [CrossRef] [PubMed]

15. Jiang, X.Z.; Yang, M.G.; Huang, L.H.; Li, C.Q.; Xing, X.W. SPAG4L, a novel nuclear envelope protein involved in the meiotic stage of spermatogenesis. DNA Cell Biol. 2011, 30, 875-882. [CrossRef] [PubMed]

16. Haque, F.; Lloyd, D.J.; Smallwood, D.T.; Dent, C.L.; Shanahan, C.M.; Fry, A.M.; Trembath, R.C.; Shackleton, S. SUN1 interacts with nuclear lamin A and cytoplasmic nesprins to provide a physical connection between the nuclear lamina and the cytoskeleton. Mol. Cell Biol. 2006, 26, 3738-3751. [CrossRef] [PubMed]

17. Starr, D.A.; Han, M. Role of ANC-1 in tethering nuclei to the actin cytoskeleton. Science 2002, 298, 406-409. [CrossRef]

18. Starr, D.A.; Fischer, J.A. KASH'n Karry: The KASH domain family of cargo-specific cytoskeletal adaptor proteins. Bioessays 2005, 27, 1136-1146. [CrossRef]

19. Bone, C.R.; Starr, D.A. Nuclear migration events throughout development. J. Cell Sci. 2016, 129, $1951-1961$. [CrossRef]

20. Gundersen, G.G.; Worman, H.J. Nuclear positioning. Cell 2013, 152, 1376-1389. [CrossRef]

21. Wilhelmsen, K.; Ketema, M.; Truong, H.; Sonnenberg, A. KASH-domain proteins in nuclear migration, anchorage and other processes. J. Cell Sci. 2006, 119 Pt 24, 5021-5029. [CrossRef] [PubMed]

22. Zhang, X.; Lei, K.; Yuan, X.; Wu, X.; Zhuang, Y.; Xu, T.; Xu, R.; Han, M. SUN1/2 and Syne/Nesprin-1/2 complexes connect centrosome to the nucleus during neurogenesis and neuronal migration in mice. Neuron 2009, 64, 173-187. [CrossRef] [PubMed]

23. Malone, C.J.; Misner, L.; Le Bot, N.; Tsai, M.C.; Campbell, J.M.; Ahringer, J.; White, J.G. The C. elegans hook protein, ZYG-12, mediates the essential attachment between the centrosome and nucleus. Cell 2003, 115, 825-836. [CrossRef]

24. Xiong, H.; Rivero, F.; Euteneuer, U.; Mondal, S.; Mana-Capelli, S.; Larochelle, D.; Vogel, A.; Gassen, B.; Noegel, A.A. Dictyostelium Sun-1 connects the centrosome to chromatin and ensures genome stability. Traffic 2008, 9, 708-724. [CrossRef] [PubMed]

25. Salpingidou, G.; Smertenko, A.; Hausmanowa-Petrucewicz, I.; Hussey, P.J.; Hutchison, C.J. A novel role for the nuclear membrane protein emerin in association of the centrosome to the outer nuclear membrane. J. Cell Biol. 2007, 178, 897-904. [CrossRef] [PubMed]

26. Roux, K.J.; Crisp, M.L.; Liu, Q.; Kim, D.; Kozlov, S.; Stewart, C.L.; Burke, B. Nesprin 4 is an outer nuclear membrane protein that can induce kinesin-mediated cell polarization. Proc. Natl. Acad. Sci. USA 2009, 106, 2194-2199. [CrossRef] [PubMed]

27. Lei, K.; Zhu, X.; Xu, R.; Shao, C.; Xu, T.; Zhuang, Y.; Han, M. Inner nuclear envelope proteins SUN1 and SUN2 play a prominent role in the DNA damage response. Curr. Biol. 2012, 22, 1609-1615. [CrossRef] [PubMed]

28. Lottersberger, F.; Karssemeijer, R.A.; Dimitrova, N.; de Lange, T. 53BP1 and the LINC complex promote microtubule-dependent DSB mobility and DNA repair. Cell 2015, 163, 880-893. [CrossRef]

29. Luxton, G.W.; Gomes, E.R.; Folker, E.S.; Vintinner, E.; Gundersen, G.G. Linear arrays of nuclear envelope proteins harness retrograde actin flow for nuclear movement. Science 2010, 329, 956-959. [CrossRef]

30. Chancellor, T.J.; Lee, J.; Thodeti, C.K.; Lele, T. Actomyosin tension exerted on the nucleus through nesprin-1 connections influences endothelial cell adhesion, migration, and cyclic strain-induced reorientation. Biophys. J. 2010, 99, 115-123. [CrossRef]

31. Nishioka, Y.; Imaizumi, H.; Imada, J.; Katahira, J.; Matsuura, N.; Hieda, M. SUN1 splice variants, SUN1_888, SUN1_785, and predominant SUN1_916, variably function in directional cell migration. Nucleus 2016, 7, 572-584. [CrossRef]

32. Hiraoka, Y.; Dernburg, A.F. The SUN rises on meiotic chromosome dynamics. Dev. Cell 2009, 17, 598-605. [CrossRef]

33. Chambliss, A.B.; Khatau, S.B.; Erdenberger, N.; Robinson, D.K.; Hodzic, D.; Longmore, G.D.; Wirtz, D. The LINC-anchored actin cap connects the extracellular milieu to the nucleus for ultrafast mechanotransduction. Sci. Rep. 2013, 3, 1087. [CrossRef] [PubMed] 
34. Dechat, T.; Adam, S.A.; Taimen, P.; Shimi, T.; Goldman, R.D. Nuclear lamins. Cold Spring Harb. Perspect. Biol. 2010, 2, a000547. [CrossRef] [PubMed]

35. Osmanagic-Myers, S.; Dechat, T.; Foisner, R. Lamins at the crossroads of mechanosignaling. Genes Dev. 2015, 29, 225-237. [PubMed]

36. Khatau, S.B.; Hale, C.M.; Stewart-Hutchinson, P.J.; Patel, M.S.; Stewart, C.L.; Searson, P.C.; Hodzic, D.; Wirtz, D. A perinuclear actin cap regulates nuclear shape. Proc. Natl. Acad. Sci. USA 2009, 106, 19017-19022. [CrossRef]

37. Lombardi, M.L.; Jaalouk, D.E.; Shanahan, C.M.; Burke, B.; Roux, K.J.; Lammerding, J. The interaction between nesprins and sun proteins at the nuclear envelope is critical for force transmission between the nucleus and cytoskeleton. J. Biol. Chem. 2011, 286, 26743-26753. [CrossRef]

38. Guilak, F. Compression-induced changes in the shape and volume of the chondrocyte nucleus. J. Biomech. 1995, 28, 1529-1541. [CrossRef]

39. Versaevel, M.; Grevesse, T.; Gabriele, S. Spatial coordination between cell and nuclear shape within micropatterned endothelial cells. Nat. Commun. 2012, 3, 671. [CrossRef] [PubMed]

40. Booth-Gauthier, E.A.; Alcoser, T.A.; Yang, G.; Dahl, K.N. Force-induced changes in subnuclear movement and rheology. Biophys. J. 2012, 103, 2423-2431. [CrossRef]

41. Poh, Y.C.; Shevtsov, S.P.; Chowdhury, F.; Wu, D.C.; Na, S.; Dundr, M.; Wang, N. Dynamic force-induced direct dissociation of protein complexes in a nuclear body in living cells. Nat. Commun. 2012, 3, 866. [CrossRef] [PubMed]

42. Matthews, B.D.; Overby, D.R.; Mannix, R.; Ingber, D.E. Cellular adaptation to mechanical stress: Role of integrins, Rho, cytoskeletal tension and mechanosensitive ion channels. J. Cell Sci. 2006, 119 Pt 3, 508-518. [CrossRef]

43. Choquet, D.; Felsenfeld, D.P.; Sheetz, M.P. Extracellular matrix rigidity causes strengthening of integrin-cytoskeleton linkages. Cell 1997, 88, 39-48. [CrossRef]

44. Guilluy, C.; Osborne, L.D.; Van Landeghem, L.; Sharek, L.; Superfine, R.; Garcia-Mata, R.; Burridge, K. Isolated nuclei adapt to force and reveal a mechanotransduction pathway in the nucleus. Nat. Cell Biol. 2014, 16, 376-381. [CrossRef]

45. Kanellos, G.; Zhou, J.; Patel, H.; Ridgway, R.A.; Huels, D.; Gurniak, C.B.; Sandilands, E.; Carragher, N.O.; Sansom, O.J.; Witke, W.; et al. ADF and cofilin1 control actin stress fibers, nuclear integrity, and cell survival. Cell Rep. 2015, 13, 1949-1964. [CrossRef] [PubMed]

46. Wiggan, O.; Schroder, B.; Krapf, D.; Bamburg, J.R.; DeLuca, J.G. Cofilin Regulates Nuclear Architecture through a Myosin-II Dependent Mechanotransduction Module. Sci. Rep. 2017, 7, 40953. [CrossRef] [PubMed]

47. Ramdas, N.M.; Shivashankar, G.V. Cytoskeletal control of nuclear morphology and chromatin organization. J. Mol. Biol. 2015, 427, 695-706. [CrossRef] [PubMed]

48. Gao, Z.; He, Q.; Peng, B.; Chiao, P.J.; Ye, J. Regulation of nuclear translocation of HDAC3 by IkappaBalpha is required for tumor necrosis factor inhibition of peroxisome proliferator-activated receptor gamma function. J. Biol. Chem. 2006, 281, 4540-4547. [CrossRef] [PubMed]

49. Jain, N.; Iyer, K.V.; Kumar, A.; Shivashankar, G.V. Cell geometric constraints induce modular gene-expression patterns via redistribution of HDAC3 regulated by actomyosin contractility. Proc. Natl. Acad. Sci. USA 2013, 110, 11349-11354. [CrossRef]

50. Zhang, X.; Cook, P.C.; Zindy, E.; Williams, C.J.; Jowitt, T.A.; Streuli, C.H.; MacDonald, A.S.; Redondo-Muñoz, J. Integrin $\alpha 4 \beta 1$ controls G9a activity that regulates epigenetic changes and nuclear properties required for lymphocyte migration. Nucleic Acids Res. 2016, 44, 3031-3044. [CrossRef]

51. Gerlitz, G.; Bustin, M. The role of chromatin structure in cell migration. Trends Cell Biol. 2011, $21,6-11$. [CrossRef] [PubMed]

52. Furusawa, T.; Rochman, M.; Taher, L.; Dimitriadis, E.K.; Nagashima, K.; Anderson, S.; Bustin, M. Chromatin decompaction by the nucleosomal binding protein HMGN5 impairs nuclear sturdiness. Nat. Commun. 2015, 6, 6138. [CrossRef] [PubMed]

53. Jackson, D.A. The principles of nuclear structure. Chromosome Res. 2003, 11, 387-401. [CrossRef] [PubMed]

54. Discher, D.E.; Janmey, P.; Wang, Y.L. Tissue cells feel and respond to the stiffness of their substrate. Science 2005, 310, 1139-1143. [CrossRef] [PubMed]

55. Uhler, C.; Shivashankar, G.V. Regulation of genome organization and gene expression by nuclear mechanotransduction. Nat. Rev. Mol. Cell Biol. 2017, 18, 717-727. [CrossRef] [PubMed] 
56. Brosig, M.; Ferralli, J.; Gelman, L.; Chiquet, M.; Chiquet-Ehrismann, R. Interfering with the connection between the nucleus and the cytoskeleton affects nuclear rotation, mechanotransduction and myogenesis. Int. J. Biochem. Cell Biol. 2010, 42, 1717-1728. [CrossRef] [PubMed]

57. Razafsky, D.W.; Hodzic, D. Nuclear Envelope in Nuclear Positioning and Cell Migration. Cancer Biol. Nucl. Envel. 2014, 471-490.

58. Khatau, S.B.; Kusuma, S.; Hanjaya-Putra, D.; Mali, P.; Cheng, L.; Lee, J.S.; Gerecht, S.; Wirtz, D. The differential formation of the LINC-mediated perinuclear actin cap in pluripotent and somatic cells. PLoS ONE 2012, 7, e36689. [CrossRef]

59. Kim, D.H.; Khatau, S.B.; Feng, Y.; Walcott, S.; Sun, S.X.; Longmore, G.D.; Wirtz, D. Actin cap associated focal adhesions and their distinct role in cellular mechanosensing. Sci. Rep. 2012, 2, 555. [CrossRef]

60. Kutscheidt, S.; Zhu, R.; Antoku, S.; Luxton, G.W.; Stagljar, I.; Fackler, O.T.; Gundersen, G.G. FHOD1 interaction with nesprin-2G mediates TAN line formation and nuclear movement. Nat. Cell Biol. 2014, 16, 708-715. [CrossRef]

61. Luxton, G.W.G.; Gomes, E.R.; Folker, E.S.; Worman, H.J.; Gundersen, G.G. TAN lines: A novel nuclear envelope structure involved in nuclear positioning. Nucleus 2011, 2, 173-181. [CrossRef] [PubMed]

62. Borrego-Pinto, J.; Jegou, T.; Osorio, D.S.; Auradé, F.; Gorjánácz, M.; Koch, B.; Mattaj, I.W.; Gomes, E.R. Samp1 is a component of TAN lines and is required for nuclear movement. J. Cell Sci. 2012, 125 Pt 5, 1099-1105. [CrossRef] [PubMed]

63. Saunders, C.A.; Harris, N.J.; Willey, P.T.; Woolums, M.; Wang, Y.; McQuown, A.J.; Schoenhofen, A.; Worman, H.J.; Dauer, W.T.; Gundersen, G.G.; et al. TorsinA controls TAN line assembly and the retrograde flow of dorsal perinuclear actin cables during rearward nuclear movement. J. Cell Biol. 2017, 216, 657-674. [CrossRef] [PubMed]

64. Arsenovic, P.T.; Ramachandran, I.; Bathula, K.; Zhu, R.; Narang, J.D.; Noll, N.A.; Lemmon, C.A.; Gundersen, G.G.; Conway, D.E. Nesprin-2G, a component of the nuclear LINC complex, is subject to myosin-dependent tension. Biophys. J. 2016, 110, 34-43. [CrossRef] [PubMed]

65. Hoffman, B.D.; Grashoff, C.; Schwartz, M.A. Dynamic molecular processes mediate cellular mechanotransduction. Nature 2011, 475, 316-323. [CrossRef]

66. Smutny, M.; Yap, A.S. Neighborly relations: Cadherins and mechanotransduction. J. Cell Biol. 2010, 189, 1075-1077. [CrossRef]

67. Wang, D.Z.; Li, S.; Hockemeyer, D.; Sutherland, L.; Wang, Z.; Schratt, G.; Richardson, J.A.; Nordheim, A.; Olson, E.N. Potentiation of serum response factor activity by a family of myocardin-related transcription factors. Proc. Natl. Acad. Sci. USA 2002, 99, 14855-14860. [CrossRef]

68. Miralles, F.; Posern, G.; Zaromytidou, A.I.; Treisman, R. Actin dynamics control SRF activity by regulation of its coactivator MAL. Cell 2003, 113, 329-342. [CrossRef]

69. Mouilleron, S.; Guettler, S.; Langer, C.A.; Treisman, R.; McDonald, N.Q. Molecular basis for G-actin binding to RPEL motifs from the serum response factor coactivator MAL. EMBO J. 2008, 27, 3198-3208. [CrossRef]

70. Pawlowski, R.; Rajakyla, E.K.; Vartiainen, M.K.; Treisman, R. An actin-regulated importin alpha/beta-dependent extended bipartite NLS directs nuclear import of MRTF-A. EMBO J. 2010, 29, 3448-3458. [CrossRef]

71. Vartiainen, M.K.; Guettler, S.; Larijani, B.; Treisman, R. Nuclear actin regulates dynamic subcellular localization and activity of the SRF cofactor MAL. Science 2007, 316, 1749-1752. [CrossRef] [PubMed]

72. Baarlink, C.; Wang, H.; Grosse, R. Nuclear actin network assembly by formins regulates the SRF coactivator MAL. Science 2013, 340, 864-867. [CrossRef] [PubMed]

73. Iyer, K.V.; Pulford, S.; Mogilner, A.; Shivashankar, G.V. Mechanical activation of cells induces chromatin remodeling preceding MKL nuclear transport. Biophys. J. 2012, 103, 1416-1428. [CrossRef] [PubMed]

74. Olson, E.N.; Nordheim, A. Linking actin dynamics and gene transcription to drive cellular motile functions. Nat. Rev. Mol. Cell Biol. 2010, 11, 353-365. [CrossRef] [PubMed]

75. Holaska, J.M.; Kowalski, A.K.; Wilson, K.L. Emerin caps the pointed end of actin filaments: Evidence for an actin cortical network at the nuclear inner membrane. PLoS Biol. 2004, 2, E231. [CrossRef] [PubMed]

76. Ho, C.Y.; Jaalouk, D.E.; Vartiainen, M.K.; Lammerding, J. Lamin A/C and emerin regulate MKL1 SRF activity by modulating actin dynamics. Nature 2013, 497, 507-511. [CrossRef] [PubMed] 
77. Lammerding, J.; Schulze, P.C.; Takahashi, T.; Kozlov, S.; Sullivan, T.; Kamm, R.D.; Stewart, C.L.; Lee, R.T. Lamin A/C deficiency causes defective nuclear mechanics and mechanotransduction. J. Clin. Investig. 2004, 113, 370-378. [CrossRef]

78. Cupesi, M.; Yoshioka, J.; Gannon, J.; Kudinova, A.; Stewart, C.L.; Lammerding, J. Attenuated hypertrophic response to pressure overload in a lamin A/C haploin sufficiency mouse. J. Mol. Cell Cardiol. 2010, 48, 1290-1297. [CrossRef]

79. Elosegui-Artola, A.; Andreu, I.; Beedle, A.E.; Lezamiz, A.; Uroz, M.; Kosmalska, A.J.; Oria, R.; Kechagia, J.Z.; Rico-Lastres, P.; Le Roux, A.L.; et al. Force triggers YAP nuclear entry by regulating transport across nuclear pores. Cell 2017, 171, 1397-1410. [CrossRef]

80. Frey, S.; Görlich, D. A saturated FG-repeat hydrogel can reproduce the permeability properties of nuclear pore complexes. Cell 2007, 130, 512-523. [CrossRef]

81. Patel, S.S.; Belmont, B.J.; Sante, J.M.; Rexach, M.F. Natively unfolded nucleoporins gate protein diffusion across the nuclear pore complex. Cell 2007, 129, 83-96. [CrossRef] [PubMed]

82. Timney, B.L.; Raveh, B.; Mironska, R.; Trivedi, J.M.; Kim, S.J.; Russel, D.; Wente, S.R.; Sali, A.; Rout, M.P. Simple rules for passive diffusion through the nuclear pore complex. J. Cell Biol. 2016, 215, 57-76. [CrossRef] [PubMed]

83. Dupont, S.; Morsut, L.; Aragona, M.; Enzo, E.; Giulitti, S.; Cordenonsi, M.; Zanconato, F.; Le Digabel, J.; Forcato, M.; Bicciato, S.; et al. Role of YAP/TAZ in mechanotransduction. Nature 2011, 474, 179-183. [CrossRef] [PubMed]

84. Zanconato, F.; Cordenonsi, M.; Piccolo, S. YAP/TAZ at the roots of cancer. Cancer Cell 2016, $29,783-803$. [CrossRef] [PubMed]

85. Plouffe, S.W.; Hong, A.W.; Guan, K.L. Disease implications of the Hippo/YAP pathway. Trends Mol. Med. 2015, 21, 212-222. [CrossRef]

86. Meng, Z.; Moroishi, T.; Guan, K.L. Mechanisms of Hippo pathway regulation. Genes Dev. 2016, 30, 1-17.

87. Driscoll, T.P.; Cosgrove, B.D.; Heo, S.J.; Shurden, Z.E.; Mauck, R.L. Cytoskeletal to nuclear strain transfer regulates YAP signaling in mesenchymal stem cells. Biophys. J. 2015, 108, 2783-2793. [CrossRef]

88. Das, A.; Fischer, R.S.; Pan, D.; Waterman, C.M. YAP nuclear localization in the absence of cell-cell contact is mediated by a filamentous actin-dependent, myosin II- and phospho-YAP-independent pathway during extracellular matrix mechanosensing. J. Biol. Chem. 2016, 291, 6096-6110. [CrossRef]

89. Aragona, M.; Panciera, T.; Manfrin, A.; Giulitti, S.; Michielin, F.; Elvassore, N.; Dupont, S.; Piccolo, S. A mechanical checkpoint controls multicellular growth through YAP/TAZ regulation by actin-processing factors. Cell 2013, 54, 1047-1059. [CrossRef]

90. Benham-Pyle, B.W.; Pruitt, B.L.; Nelson, W.J. Cell adhesion. Mechanical strain induces E-cadherin-dependent Yap1 and $\beta$-catenin activation to drive cell cycle entry. Science 2015, 348, 1024-1027. [CrossRef]

91. Valon, L.; Marín-Llauradó, A.; Wyatt, T.; Charras, G.; Trepat, X. Optogenetic control of cellular forces and mechanotransduction. Nat. Commun. 2017, 8, 14396. [CrossRef] [PubMed]

92. Liu, Q.; Pante, N.; Misteli, T.; Elsagga, M.; Crisp, M.; Hodzic, D.; Burke, B.; Roux, K.J. Functional association of Sun1 with nuclear pore complexes. J. Cell Biol. 2007, 178, 785-798. [CrossRef] [PubMed]

93. Lu, W.; Gotzmann, J.; Sironi, L.; Jaeger, V.M.; Schneider, M.; Lüke, Y.; Uhlén, M.; Szigyarto, C.A.; Brachner, A.; Ellenberg, J.; et al. Sun1 forms immobile macromolecular assemblies at the nuclear envelope. Biochim. Biophys. Acta 2008, 1783, 2415-2426. [CrossRef] [PubMed]

94. Li, P.; Noegel, A.A. Inner nuclear envelope protein SUN1 plays a prominent role in mammalian mRNA export. Nucleic Acids Res. 2015, 43, 9874-9888. [CrossRef] [PubMed]

95. Hale, C.M.; Shrestha, A.L.; Khatau, S.B.; Stewart-Hutchinson, P.J.; Hernandez, L.; Stewart, C.L.; Hodzic, D.; Wirtz, D. Dysfunctional connections between the nucleus and the actin and microtubule networks in laminopathic models. Biophys. J. 2008, 95, 5462-5475. [CrossRef] [PubMed]

96. Luxton, G.W.; Starr, D.A. KASHing up with the nucleus: Novel functional roles of KASH proteins at the cytoplasmic surface of the nucleus. Curr. Opin. Cell Biol. 2014, 28, 69-75. [CrossRef] [PubMed]

97. Chang, W.; Folker, E.S.; Worman, H.J.; Gundersen, G.G. Emerin organizes actin flow for nuclear movement and centrosome orientation in migrating fibroblasts. Mol. Biol. Cell 2013, 24, 3869-3880. [CrossRef]

98. Stewart, R.M.; Zubek, A.E.; Rosowski, K.A.; Schreiner, S.M.; Horsley, V.; King, M.C. Nuclear-cytoskeletal linkages facilitate cross talk between the nucleus and intercellular adhesions. J. Cell Biol. 2015, 209, 403-418. [CrossRef] 
99. Revach, O.Y.; Weiner, A.; Rechav, K.; Sabanay, I.; Livne, A.; Geiger, B. Mechanical interplay between invadopodia and the nucleus in cultured cancer cells. Sci. Rep. 2015, 5, 9466. [CrossRef]

100. Gimpel, P.; Lee, Y.L.; Sobota, R.M.; Calvi, A.; Koullourou, V.; Patel, R.; Mamchaoui, K.; Nédélec, F.; Shackleton, S.; Schmoranzer, J.; et al. Nesprin-1 $\alpha$ dependent microtubule nucleation from the nuclear envelope via Akap450 is necessary for nuclear positioning in muscle cells. Curr. Biol. 2017, 27, 2999-3009. [CrossRef]

101. Myat, M.M.; Rashmi, R.N.; Manna, D.; Xu, N.; Patel, U.; Galiano, M.; Zielinski, K.; Lam, A.; Welte, M.A. Drosophila KASH-domain protein Klarsicht regulates microtubule stability and integrin receptor localization during collective cell migration. Dev. Biol. 2015, 407, 103-114. [CrossRef] [PubMed]

102. Matsumoto, A.; Hieda, M.; Yokoyama, Y.; Nishioka, Y.; Yoshidome, K.; Tsujimoto, M.; Matsuura, N. Global loss of a nuclear lamina component, lamin A/C, and LINC complex components SUN1, SUN2, and nesprin-2 in breast cancer. Cancer Med. 2015, 4, 1547-1557. [CrossRef] [PubMed]

103. Schreiber, K.H.; Kennedy, B.K. When lamins go bad: Nuclear structure and disease. Cell 2013, 152, $1365-1375$. [CrossRef] [PubMed]

104. Le, H.Q.; Ghatak, S.; Yeung, C.Y.; Tellkamp, F.; Günschmann, C.; Dieterich, C.; Yeroslaviz, A.; Habermann, B.; Pombo, A.; Niessen, C.M.; et al. Mechanical regulation of transcription controls Polycomb-mediated gene silencing during lineage commitment. Nat. Cell Biol. 2016, 18, 864-875. [CrossRef] [PubMed]

105. Cho, S.; Irianto, J.; Discher, D.E. Mechanosensing by the nucleus: From pathways to scaling relationships. J. Cell Biol. 2017, 216, 305-315. [CrossRef] [PubMed]

106. Tan, K.L.; Haelterman, N.A.; Kwartler, C.S.; Regalado, E.S.; Lee, P.T.; Nagarkar-Jaiswal, S.; Guo, D.C.; Duraine, L.; Wangler, M.F.; University of Washington Center for Mendelian Genomics; et al. Ari-1 regulates myonuclear organization together with Parkin and is associated with aortic aneurysms. Dev. Cell 2018, 45, 226-244. [CrossRef] [PubMed]

107. Cain, N.E.; Jahed, Z.; Schoenhofen, A.; Valdez, V.A.; Elkin, B.; Hao, H.; Harris, N.J.; Herrera, L.A.; Woolums, B.M.; Mofrad, M.R.K.; et al. Conserved SUN-KASH Interfaces Mediate LINC Complex-Dependent Nuclear Movement and Positioning. Curr. Biol. 2018, 28, 3086-3097. [CrossRef] [PubMed]

108. Jahed, Z.; Vu, U.T.; Fadavi, D.; Ke, H.; Rathish, A.; Kim, S.C.J.; Feng, W.; Mofrad, M.R.K. A molecular model for LINC complex regulation: Activation of SUN2 for KASH binding. Mol. Biol. Cell 2018, 29, 2012-2023. [CrossRef]

109. Versaevel, M.; Braquenier, J.B.; Riaz, M.; Grevesse, T.; Lantoine, J.; Gabriele, S. Super-resolution microscopy reveals LINC complex recruitment at nuclear indentation sites. Sci. Rep. 2014, 4, 7362. [CrossRef]

110. Gerlitz, G.; Bustin, M. Efficient cell migration requires global chromatin condensation. J. Cell Sci. 2010, 123 Pt 13, 2207-2217. [CrossRef]

111. Yokoyama, Y.; Hieda, M.; Nishioka, Y.; Matsumoto, A.; Higashi, S.; Kimura, H.; Yamamoto, H.; Mori, M.; Matsuura, S.; Matsuura, N. Cancer-associated upregulation of histone H3 lysine 9 trimethylation promotes cell motility in vitro and drives tumor formation in vivo. Cancer Sci. 2013, 104, 889-895. [CrossRef] [PubMed] 